Article

\title{
Heat Transmission Coefficient Measurements in Buildings Utilizing a Heat Loss Measuring Device
}

\section{Lars Schiøtt Sørensen}

Danish Building Research Institute, Aalborg University, A.C. Meyers Vænge 15, Copenhagen 2450, Denmark; E-Mail: LSS@sbi.aau.dk; Tel. (mobile): +45-29-10-0296; Tel.: +45-99-40-2500;

Fax: $+45-45-86-7535$

Received: 25 May 2013; in revised form: 9 August 2013 / Accepted: 2 August 2013 /

Published: 21 August 2013

\begin{abstract}
Global energy efficiency can be obtained in two ordinary ways. One way is to improve the energy production and supply side, and the other way is, in general, to reduce the consumption of energy in society. This paper has focus on the latter and especially the consumption of energy for heating and cooling our houses. There is a huge energy-saving potential in this area for reducing both the global climate problems as well as economy challenges. Heating of buildings in Denmark accounts for approximately $40 \%$ of the entire national energy consumption. For this reason, a reduction of heat losses from building envelopes are of great importance in order to reach the Bologna $\mathrm{CO}_{2}$ emission reduction targets. Upgrading of the energy performance of buildings is a topic of huge global interest these years. Not only heating in the temperate and arctic regions are important, but also air conditioning and mechanical ventilation in the "warm countries" contribute to an enormous energy consumption and corresponding $\mathrm{CO}_{2}$ emission. In order to establish the best basis for upgrading the energy performance, it is important to make measurements of the heat losses at different places on a building facade, in order to optimize the energy performance. This paper presents a method for measuring the heat loss by utilizing a U-value meter. The $\mathrm{U}$-value meter measures the heat transfer in the unit $\mathrm{W} / \mathrm{Km}^{2}$ and has been used in several projects to upgrade the energy performance in temperate regions. The U-value meter was also utilized in an EUDP (Energy Technological Development and Demonstration Program) focusing on renovation of houses from the 1960s and 1970s.
\end{abstract}

Keywords: energy reduction of buildings; heat loss measuring; energy performance; heat loss measuring device; temperate regions; $\mathrm{CO}_{2}$ emission; global climate 


\section{Introduction}

\subsection{Introduction to Energy Performance Upgrading}

Around the world, building owners are able to decrease heating costs remarkably with a rational upgrading of the energy performance of their buildings. This is demonstrated by measurements of different houses, built in different decades of the past century [1,2]. A few examples are described for houses from the 1960 s and 1970 s in this paper.

Heating accounts for some $40 \%$ of the total Danish energy consumption which, therefore, represents vast potential savings. The U-value meter is an ideal instrument by which to establish the locations of the greatest heat loss on a facade, arming owners with the knowledge of where best to concentrate efforts to insulate and optimize savings [3]. In this way, the overall costs of upgrading the energy performance can be reduced considerably, and an optimal relation between investment and savings achieved.

The mean ambient temperature in Denmark has increased by about $1.2^{\circ} \mathrm{C}$ during a period of approximately 130 years [4]. The period encompasses a part of the industrial revolution, which began during the second half of the 18th century. Upgrading the energy performance of as many houses as possible worldwide would benefit the environment by slowing and decreasing the consequent global heating.

A EUDP project with the aim of designing standardized solutions for energy renovation of facades is currently in progress [5]. In the project, the U-value meter is utilized to measure representative U-values for a number of different residential houses built in the period from 1960s to1970s and representing over $90 \%$ of private houses in Denmark. The measurements will be compared with the U-value requirements for the respective construction periods. From this approach we are able to calculate the potential heat savings compared with the present U-value requirements, as per the Danish Building Regulations. Furthermore, we compare heat consumption before and after upgrading the energy performance where the developed standard solutions for retrofitting facades are used. The involved parties are, among others, HT-Meter ApS., Saint-Gobain Isover A/S together with Technical University of Denmark. The project aims to minimize the emission of $\mathrm{CO}_{2}$ caused by unnecessarily large energy consumption for heating $[2,5]$.

\subsection{Introduction to U-Value Meter}

Measurements of U-values have traditionally been made in laboratories with the assistance of heat flux measurements and heat conductivity apparatus [3]. Such measurement methods are complicated and laborious because the target wall or window elements must be transported to the laboratory and mounted into the test arrangement designed for the experiment. Then controlled amounts of energy, resulting in rises in temperature, must be supplied to the test arrangement in order to initiate the essential heat transfer in the test piece.

Fourier's law $\Phi=\mathrm{k} \Delta \mathrm{T} / \Delta \mathrm{x}$ (a special 1D form of Fourier's law [6,7]) representing heat conduction, only applies to the steady-state. Laboratory measurements of U-values can take several hours or even days before a steady-state measurement can be obtained. 
There exist some test arrangements that can be brought to a building where the heat loss or a thermal conductivity is being researched. For instance Gerike [8] describes a temperature sensing device adapted to maximize heat transfer from a selected location to the device and Chuah et al.[9] claims an insulating measuring apparatus which forces heat flow in one direction within a constant temperature region. Incorporated is an electronically controlled heating device used to form a region of constant high temperature on one side of the insulating material causing the majority of heat transfer to concentrate in a longitudinal heat flux, which flows across the thickness of a test piece effecting a one-dimensional heat transfer. Another thermal sensor device that is available in the market is the Hukseflux Thermal Sensor. Others patented types worth a mention include those mentioned in U.S. Patent 4,647,221 [10], U.S. Patent 4,236,403 [11] and E.P. Patent 0,065,433[12].

However, none of these above mentioned apparatus or arrangements provides a measuring device for heat transmission coefficients or thermal conductivities where an air gap is provided between the surface of the test piece and a sensor plate (heat absorption sensor) as is achieved by the U-value meter. Furthermore, several of those mentioned force heat through the test piece via different electronic equipment techniques. Others measure an electrical resistance between the surfaces of the test piece according to the temperature difference of the two surfaces and gain an estimate of the heat transmission coefficient calculated from this observed electrical resistance. A rather inaccurate result is obtained this way.

Finally, on most of the reported existing apparatus, it is necessary to mount some of the test equipment on the test piece leaving some cracks or drill holes on the object. For all of the existing apparatus there is direct contact between the heat absorption sensor (sensor plate) and the surface of the test piece, thereby seriously affecting the result due to the transition insulation factor caused by the air gained insulating effect near the surfaces

The time required to reach a steady-state situation depends primarily on the thermal inertia of the test piece, i.e., material-based properties such as heat capacity, density, thermal conductivity and material thickness. After that, measurements of the heat flux are typically carried out for a relatively long period of time. This is done by means of measurements in test arrangements, which are large in volume, typically several cubic meters. The heat flux is measured by holding a constant temperature level on the heat receiving side, i.e., the cold side of the test piece. The basis for finding heat conductivities practically is by means of laboratory-based measurements on conditioned test specimens brought to steady state by means of a plate apparatus with a protective ring or with a heat flux meter in accordance with DS/EN 12664 [13] or DS/EN 12667 [14]. The results of the measurements refer to a mean temperature of $10^{\circ} \mathrm{C}$. Common to the aforementioned measuring methods is the problem of a transition insulation factor at the bounding surfaces on the two sides of a test piece. The surface temperatures of the test piece are not identical to the air temperatures very near to its surfaces.

With the newly developed U-value meter, such a process can be omitted and U-values can be measured directly on site. See Figure 1 for a picture of the U-value meter.

This apparatus is based on a principle where the heat is "trapped" by a heat absorption sensor (copper plate) when it leaves the outdoor surface of the test piece. A copper plate is used, as the absorption sensor due to its high thermal diffusivity and high conductivity [2,3].

The temperature of the heat absorption sensor is measured continuously over a short period of time, and from the relative increase of energy the U-value can be calculated. The system is separated 
from the surrounding environment by a highly insulating material, with low thermal diffusivity and low conductivity.

Figure 1. U-value measurement on outer wall. The figure also shows an insulated acclimation suitcase, in which the meter is placed between the individual measurements.
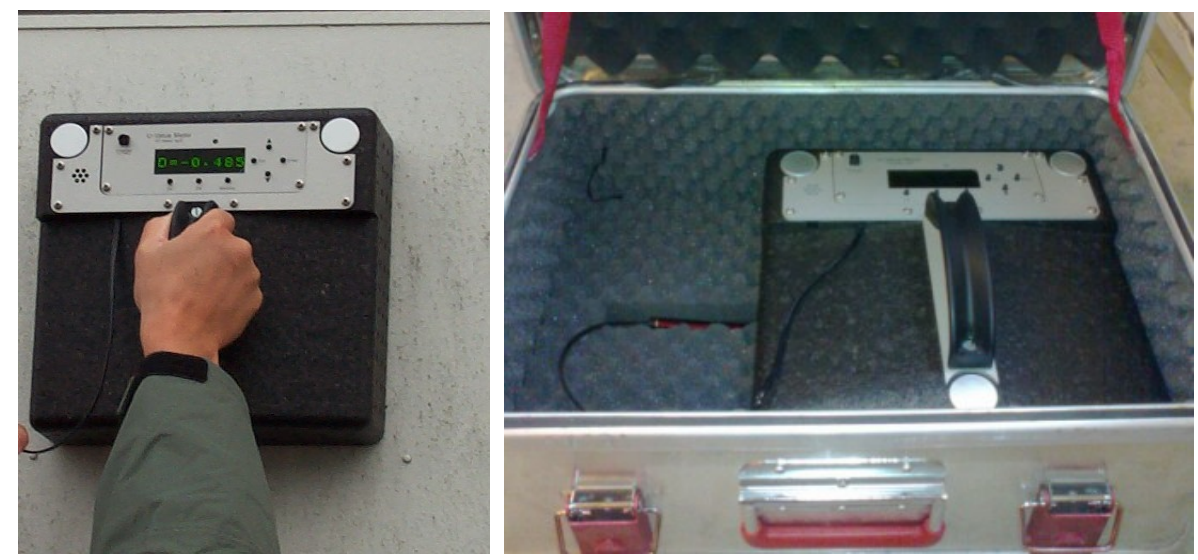

The measuring procedure for the U-value Meter is outlined in a detailed way below:

(1). If the Meter is taken outdoors from an indoor environment the Meter has to be acclimatized to the outdoor temperature for a minimum period of half an hour. The display will show "Waiting", until the Meter is in thermal equilibrium with its surroundings. While waiting, the Meter can display the difference between the reference sensor and the heat absorption sensor temperatures.

(2). After acclimatization the user is prompted to key in the indoor temperature. After that, the user is asked to hold the reference sensor up in the air, and the outdoor temperature is measured for half a minute. During data acquisition these temperature values are given as input to the main processor. In fact, the outdoor temperature is continuously measured by the reference sensor and can be displayed at any time while the apparatus is turned on.

(3). When thermal equilibrium is reached, the display says "Ready" and the user can initiate the measurement. If the user, by accident, turns the Meter towards the sun or puts his hand on the heat absorption sensor, causing a thermal rise in the heat absorption sensor, the processor will show the message "Waiting..." again, indication lack of thermal balance. Thermal equilibrium is reached when the temperature difference between the heat absorption sensor and the reference sensor is below $0.3^{\circ} \mathrm{C}$.

(4). When the user holds the Meter against the test piece, the main processor starts to count the time and the measuring process is going on for the entire measuring period ( 20 seconds). The display shows "Measuring..." and displays the temperature rise of the heat absorption sensor, while the measurement goes on.

(5). Immediately after the measurement is finished, the display says "Calculate..." for a few seconds and the U-value is presented afterwards.

(6). The user can store the results in an internal memory by pressing the button "Memory".

(7). The Meter will display "Waiting..." until the heat absorption sensor is back in thermal equilibrium with the outdoor temperature, and after that a new measurement can begin. 
Heat transfer occurs by thermal radiation, conduction and convection and the apparatus is designed to ensure that these constituent energy components are collected by the sensor plate. In fact, in the case of windows, radiation alone can account for as much as $70 \%$ of its total heat loss. However, this value can be reduced drastically with a low emissivity coating: windows with and without these coatings can be handled by the U-value meter.

Heat conduction is the molecular oscillation transport whereas radiation is electromagnetic energy transport. In the U-value meter it is chosen to transform the heat conduction (conduction in a solid) to convection in a fluid (an air gap in front of the copper plate is included to do this). That is to say, the transfer process to the heat absorption sensor is changed from conduction to convection through the air gap. It is important to ensure that the temperature of the heat absorption sensor is identical with the outdoor temperature just before a heat transmission coefficient (i.e., U-value) measurement is initiated [3].

The heat absorption sensor is coated with a material of high heat absorption capacity to secure a quick and effective heat transfer from test piece to heat absorption sensor. Heat transfer occurs by convection as well as thermal radiation via the described air gap. Following this procedure, there is no ongoing heat transfer from the surface of the test piece to the heat absorption sensor by direct contact.

By the new "air gap" technique, developed with this U-value meter, the transition insulation factors are measured as a part of the total thermal resistance of the facade and therefore included in the transmission coefficient, creating more accurate results. At the same time, geometrical inaccuracies at the surface of the test piece are eliminated by the air gap. These would, by direct contact, cause irregular heat conduction between the two surfaces, i.e., between the test piece and the copper plate.

The coating is placed on the side of the heat absorption sensor facing the test piece. On the opposite side, i.e., facing away from the test piece, a reflecting layer is placed to ensure energy transmitted to the heat absorption sensor is trapped and kept inside during the test.

Behind the reflecting foil is a heat insulating layer, of relatively thick dimensions, and low thermal conductivity and diffusivity as basic thermal properties $[2,3]$.

Another advantage of the invention is that the U-values are measured on site and in real time, giving current information of transmission coefficients for a particular building as opposed to the "new building element" U-value. This is important for several reasons: first of all, the moisture content changes in a building element, an outer wall for instance, during the years in which the element is a part of the building. Moisture levels influence the U-value, depending on the relative humidity and the type of material in focus. Furthermore, the insulation in an outer wall can "fall down" a bit during the years, resulting in poorly distributed insulation. For windows, the glazing can puncture and the insulating effect is reduced significantly $[2,3]$.

\subsection{Main Processor}

One of the main objectives of the processor in the U-value device is to solve Fourier's heat transfer equation for a steady-state situation [1,6]. This equation, in differential form, can be expressed as:

$$
\Phi=\mathrm{k} \cdot \mathrm{dT} / \mathrm{dx}
$$

where $\mathrm{dT} / \mathrm{dx}$ is the temperature gradient through a homogenous material, in the direction of the heat transfer [6]. The equation represents the heat loss in Joules per second for each square meter of the test 
piece. The apparatus is intended mainly for existing buildings where a steady-state heat flow is already obtained. What are the conditions for a steady state in buildings? The outdoor conditions may have a large effect on the measurements. Especially the outdoor temperature, solar radiation, night sky radiation and winds are changing constantly. The time until a heat flow reach a steady state is called the thermal penetration time and depends on the thermal inertia of the actual building element. Of these reasons, the measurements have to be done in most stable periods (relatively constant outdoor temperature, constant low wind speed, no direct solar radiation on the facades/windows, no rain).

The heat loss expressed by the above differential equation (1) is integrated by the processor during a fixed measuring period of $20 \mathrm{~s}$. The energy is transmitted to and captured by the heat absorption sensor through a "five layer thermal system". The total transport of energy from the surface of the test object to the surface of the heat absorption sensor takes place by means of two separate processes (convective heat transmission and thermal radiation)

The heat transmission coefficient, or U-value, is obtained this way: The summarized energy in the heat absorption sensor will raise the temperature in the sensor to a level corresponding to the new level of internal energy [15], governed by the product:

$$
\mathrm{m}_{\mathrm{cu}} \cdot \mathrm{c}_{\mathrm{cu}} \cdot \Delta \mathrm{T}_{\mathrm{cu}}
$$

where $\mathrm{m}_{\mathrm{cu}}$ is the mass and $\mathrm{c}_{\mathrm{cu}}$ is the specific heat capacity of the heat absorption sensor. $\Delta \mathrm{T}_{\mathrm{cu}}$ is the temperature rise in the heat absorption sensor during the measuring period [2,3].

Therefore, the rise in level of internal energy should equal the amount of energy transmitted to the heat absorption sensor, which can be expressed as in equation 3 :

$$
\Sigma\left(\Phi_{\mathrm{c}}+\Phi_{\mathrm{r}}\right)_{\mathrm{i}} \Delta \mathrm{t}_{\mathrm{i}}
$$

where $\Phi_{\mathrm{c}}$ is the convective heat flux and $\Phi_{\mathrm{r}}$ the radiative heat flux. $\Delta \mathrm{t}_{\mathrm{i}}$ is $1 \mathrm{~s}$ intervals over which the sensor energy integration is performed. The energy is integrated over the measurement period, i.e., $20 \mathrm{~s}$. The heat transmission coefficient through a multilayer slab with thermal resistances at the inner and outer surfaces is defined by:

$$
1 / \mathrm{U}=\Sigma \mathrm{d} \mathrm{X}_{\mathrm{i}} / \mathrm{k}_{\mathrm{i}}+\mathrm{R}_{\mathrm{in}}+\mathrm{R}_{\text {out }}
$$

where $R_{\text {in }}$ and $R_{\text {out }}$ are the interface resistances from the air layer at the inner and outer surfaces respectively. $\mathrm{dX}_{\mathrm{i}}$ is the thickness in meter of layer number " $\mathrm{i}$ " in a composite construction, and $\mathrm{k}_{\mathrm{i}}$ is that layer's corresponding heat conduction coefficient in $[\mathrm{W} / \mathrm{m} \cdot \mathrm{K}]$. We also need to take the area of the heat absorption sensor plate into consideration [2]. The equation:

$$
\Sigma\left(\Phi_{\mathrm{c}}+\Phi_{\mathrm{r}}\right)_{\mathrm{i}} \Delta \mathrm{t}_{\mathrm{i}} \cdot \mathrm{A}=\mathrm{m}_{\mathrm{cu}} \cdot \mathrm{c}_{\mathrm{cu}} \cdot \Delta \mathrm{T}_{\mathrm{cu}}
$$

where $\mathrm{A}$ is the area $\left(\mathrm{m}^{2}\right)$ of the heat absorption sensor plate is the main equation, and it is solved taking the following relation from $[2,3]$ into account:

$$
\Phi=\left(\Phi_{\mathrm{c}}+\Phi_{\mathrm{r}}\right) \cdot \mathrm{A}=\mathrm{U} \cdot \mathrm{A} \cdot\left(\mathrm{T}_{\mathrm{in}}-\mathrm{T}_{\mathrm{out}}\right)
$$


$\mathrm{T}_{\text {in }}$ and $\mathrm{T}_{\mathrm{out}}$ are the absolute indoor and outdoor temperatures, respectively. From (6) we are able to get the U-value expression as:

$$
\mathrm{U}=\left(\Phi_{\mathrm{c}}+\Phi_{\mathrm{r}}\right) \cdot \mathrm{A} /\left(\mathrm{T}_{\text {in }}-\mathrm{T}_{\text {out }}\right) \cdot \mathrm{A}
$$

By multiplying numerator and denominator with the measuring time $\Delta \mathrm{t}(=20 \mathrm{~s})$ and utilizing the relations given by (5) noting that $\Delta \mathrm{t}=\Sigma \Delta \mathrm{t}_{\mathrm{i}}$, we get:

$$
\mathrm{U}=\mathrm{m}_{\mathrm{cu}} \cdot \mathrm{c}_{\mathrm{cu}} \cdot \Delta \mathrm{T}_{\mathrm{cu}} /\left(\mathrm{T}_{\mathrm{in}}-\mathrm{T}_{\mathrm{out}}\right) \cdot \mathrm{A} \cdot \Delta \mathrm{t}
$$

Therefore, before a measurement is started, we need to know the temperatures on both sides of the test object, i.e., $\mathrm{T}_{\text {in }}$ and $\mathrm{T}_{\text {out }}$ respectively. The apparatus is able to measure $\mathrm{T}_{\text {out }}$ automatically. A measuring period $\Delta \mathrm{t}$ of just $20 \mathrm{~s}$ is selected. $\Delta \mathrm{t}$ is selected to $20 \mathrm{~s}$ for every measurement, and the instrument is adjusted according to this. The heat transfer from the surface of the test object to the sensor happens through a slightly nonlinear process due to the interaction between the surface of the façade and the increasing temperature of the sensor plate during the measuring period. By selecting the same, and very short measuring time, this nonlinearity phenomenon is reduced significant.

It is beyond the scope of this presentation to present in detail the form of the related data processing algorithm in the main processor, including output validation. However, the data processing aims to solve the above described thermo-physics. For further information see [2].

\section{EUDP Project}

In Denmark, there is a great energy saving potential in houses built in the 1960s and 1970s. Special scrutiny is given to these houses since they account for a large part of the total residential dwellings [16,17]. In principle, it is possible to upgrade the energy performance of all types of housing up to modern requirements. It just depends on a sufficient increase of insulation in facades and ceiling, replacing traditional double-glazing with energy-saving glazing of low $U$-value $\left(<1.1 \mathrm{~W} / \mathrm{m}^{2} \mathrm{~K}\right)$, mounting draught-exclusion strips around doors and windows, optimizing heating systems, changing to energy saving light sources and, crucially, on willingness to pay up-front costs for hidden benefits [18-20].

During a EUPD project [6] with participants from the Technical University of Denmark, Saint-Gobain, Weber, Isolink, HT-Meter and others, measurements were made on typical residential houses from the 1960s and 1970s. As an example Table 1 presents measurement results (U-values) for a $145 \mathrm{~m}^{2}$ house built in 1964, located at Christianshøjvej, Kirke Værløse, Denmark. The house was partly rebuilt and extended in 2005, i.e., before the measurements. The outer walls are made of solid aircrete blocks. Some of the outer walls were insulated (inside) during the conversion in 2005. Heating of the house was done via a new condensing natural gas boiler. The U-measurements were made on 6 April 2011 between 9:30 a.m. and 12:10 p.m. by the U-value Meter (software version 1.60) together with a RayTek laser/infrared temperature measuring device. Weather conditions were calm, with wind speed $<5 \mathrm{~m} / \mathrm{s}$, no rain and with outdoor temperatures ranging from $8.0{ }^{\circ} \mathrm{C}$ at 9:30 a.m. and increasing to $10.0{ }^{\circ} \mathrm{C}$ at $12: 10$ p.m. The U-vale measurements were accompanied by thermography, and a few examples of these are shown in Figures 3 to 5. A plan drawing of the house is shown in Figure 2. 
Figure 2. One of the test houses involved in the Energy Technological Development and Demonstration Program (EUDP) project.
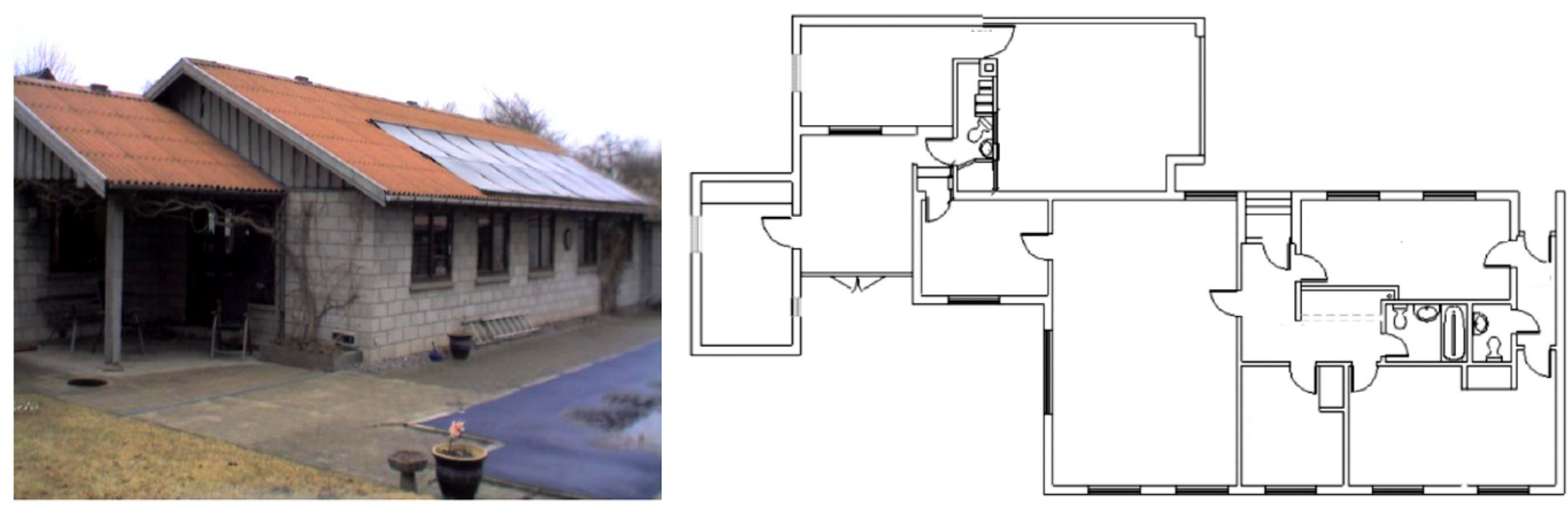

$T_{\text {in }}$ is higher than $T_{\text {out }}$ for the situations in Figures 3-5. Figures 3 and 4 show photos and thermographics taken from outside the building and Figure 5 is from inside the building. The dark shaded (blue/violet) areas on Figures 3 and 4 represent cold surfaces and therby more heat insulated than the yellow/orange areas with higher outside surface temperatures caused by poor insulation.

At the thermography on Figure 5, the dark shaded areas also represents cold surfaces, but with low heat insulation. The low insulation gives rise to low surface temperatures inside. The yellow and orange areas represent better insulated areas and therefore capable to keep the heat inside the room which in turn results in higher surface temperatures.

Figure 3. Poorly insulated window/door section along a corridor that connects the main house with an annex.
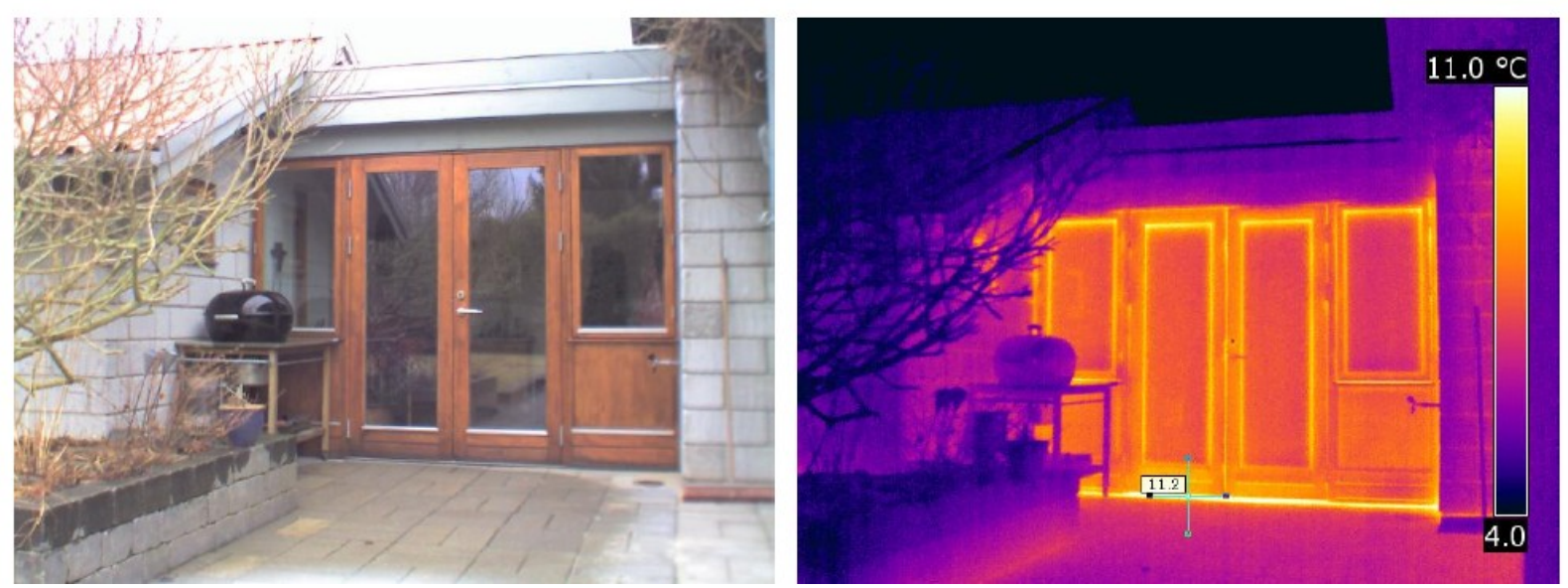

The U-value is measured to be U-value $=1.44$ ( $\mathrm{Id} 1$, the wood parapet). The outer wall next to the wind/door section was measured to be U-value $=0.80$ (Id 2). See Table 1 for measured U-values and corresponding identification (Id-numbers). 
Figure 4. Gable (west) with window to the bedroom.

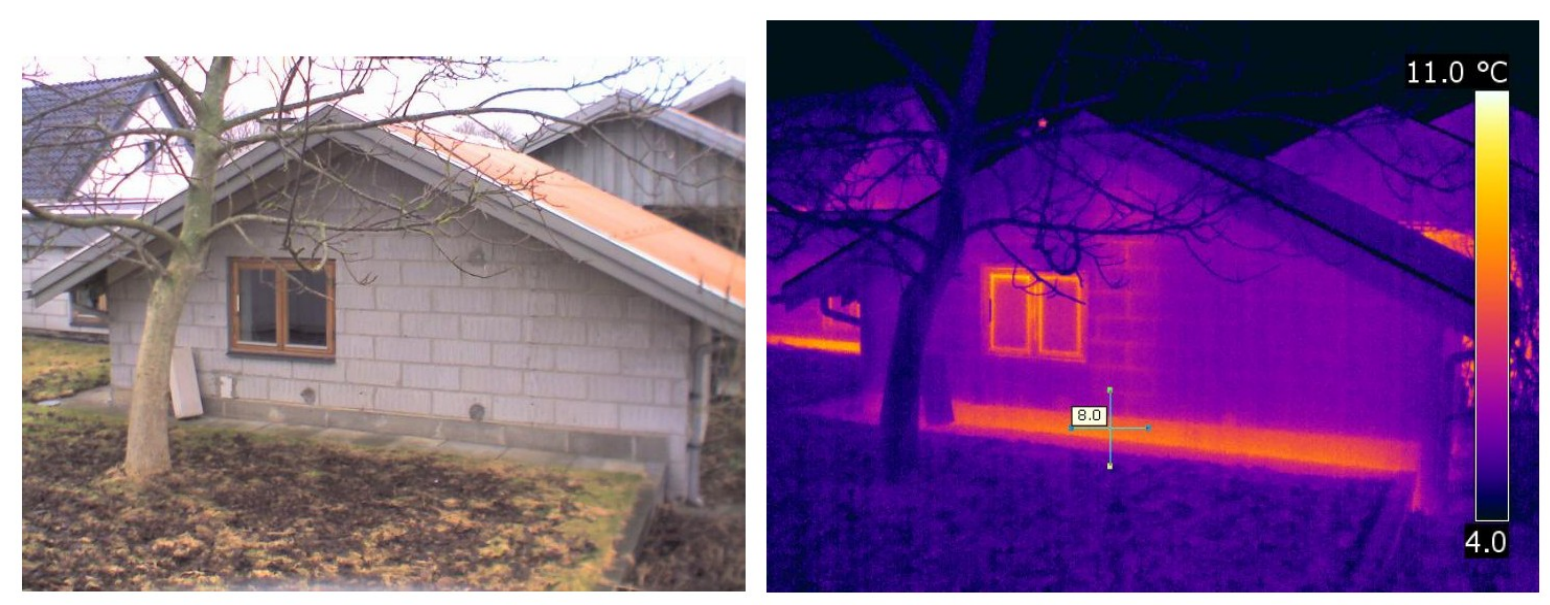

This room's outer wall was previously insulated from inside. However, a thermal bridge interruption was omitted along the floor concrete slab and therfore the socket shows orange on the thermography to the right. The U-value was measured to 1.03 (Id 19) compared with the insulated outerwall $\mathrm{U}$-value $=0.32($ Id 22), see Table 1 .

Figure 5. The transition between the wall and the floor is acceptable.

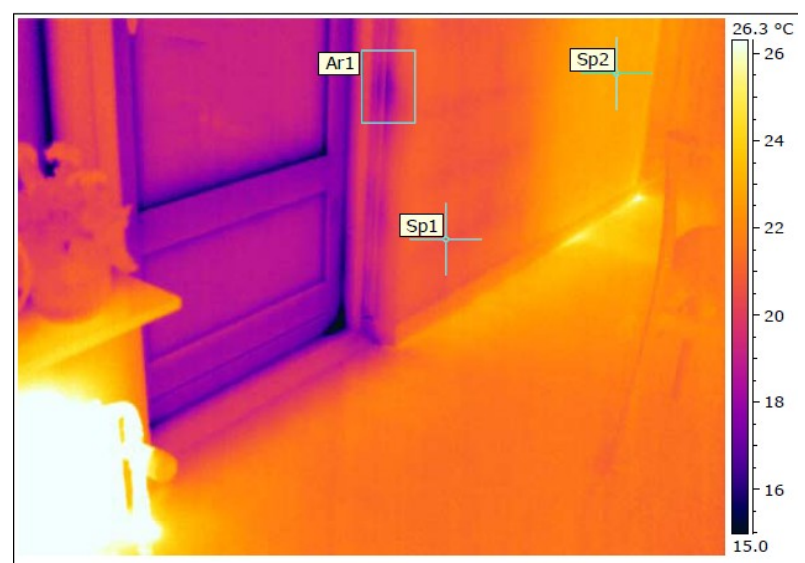

No leaks were registered in this door. The dark shades of the door indicate cold surfaces and a relatively large heat loss through the door. That corresponds to a high U-value, which is confirmed by Table 1 , where the door is measured to U-value $=1.72$ (Id 9) compared with the outer wall's $\mathrm{U}$-value $=0.89($ Id 11).

Based on the measured U-values in Table 1, thermography and measurements of surface areas for the different types of structures and building elements (outer walls, exterior doors, windows etc.), it is possible to calculate potential reduction (saving) in energy (Q) for heating with the renovation in 2005 as reference-level. If the upgraded energy performance complies with the current requirements to U-values stipulated in the Building Regulations is implemented [21-23], we can write:

$$
\mathrm{Q}=\Sigma \Phi_{\mathrm{i}} \cdot \mathrm{t}=\Sigma \mathrm{U}_{\mathrm{i}} \cdot \mathrm{A}_{\mathrm{i}} \cdot\left(\mathrm{T}_{\mathrm{in}}-\mathrm{T}_{\text {out }}\right) \cdot \mathrm{t}
$$

$U_{i}$ and $A_{i}$ are $U$-values and areas, respectively, for the building elements (windows, exterior doors, outer walls). $t$ represents the time (could be set to a year) if we use an average indoor temperature and 
the year mean temperature. The Q-equation (9) is calculated for measured $U_{i}$ as well as for required

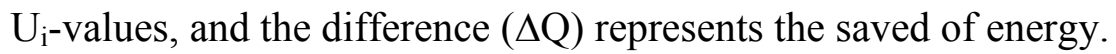

Table 1. Measurements of U-values for a typical Danish residential house from the 1960s.

\begin{tabular}{|c|c|c|c|c|}
\hline Id & Object & $\mathbf{T}_{\text {in }}\left({ }^{\circ} \mathbf{C}\right)$ & Remark & U-value $\left(\mathrm{W} / \mathbf{m}^{2} \mathbf{K}\right)$ \\
\hline 1 & Parapet & 21.9 & $\begin{array}{c}2 \text { thin wooden boards with air/insulation } \\
\text { between. } 3 \mathrm{~cm} \text { thick in total }\end{array}$ & 1.44 \\
\hline 2 & Outer wall & 23.0 & Measured at $70 \mathrm{~cm}$ height & 0.80 \\
\hline 3 & Outer wall & 22.4 & Measured at $1.5 \mathrm{~m}$ height & 0.84 \\
\hline 4 & Outer wall & 23.3 & Measured at $1.5 \mathrm{~m}$ height & 0.88 \\
\hline 5 & Pane & 23.3 & Measured at the middle of the pane & 1.24 \\
\hline 6 & Outer wall & 23.3 & Measured at $1.5 \mathrm{~m}$ height & 0.87 \\
\hline 7 & Outer wall & 23.5 & Measured at $1.5 \mathrm{~m}$ height & 0.81 \\
\hline 8 & Outer wall & 23.5 & Measured at $1.5 \mathrm{~m}$ height & 0.85 \\
\hline 9 & Exterior door & 22.0 & Door made of $4 \mathrm{~cm}$ thick wood (possibly teak) & 1.72 \\
\hline 10 & Pane & 22.3 & Measured at the middle of the pane & 1.30 \\
\hline 11 & Outer wall & 22.3 & Measured at $1.5 \mathrm{~m}$ height & 0.89 \\
\hline 12 & Beam & 22.3 & Window lintel (lightweight concrete) & 1.12 \\
\hline 13 & Edge of wall & 22.3 & No significant peripheral effects were measured & 0.91 \\
\hline 14 & Exterior door & 22.0 & Door made of $4 \mathrm{~cm}$ thick wood (possibly teak) & 1.78 \\
\hline 15 & Wall & 22.4 & Wall between the garage and living room & 0.32 \\
\hline 16 & Outer wall & 20.5 & $\begin{array}{l}\text { Outer wall of utility room/laundry room } \\
\text { (facade) }\end{array}$ & 0.26 \\
\hline 17 & Outer wall & 20.5 & Outer wall of utility room/laundry room (gable) & 0.29 \\
\hline 18 & Outer wall & 20.5 & Outer wall of utility room/laundry room (gable) & 0.29 \\
\hline 19 & Socket & 21.9 & Measured at the center of the base & 1.03 \\
\hline 20 & Outer wall & 22.7 & $\begin{array}{l}\text { Built-in cupboard stood up against this wall. } \\
\text { Measured at } 40 \mathrm{~cm} \text { height }\end{array}$ & 0.36 \\
\hline 21 & Pane & 22.7 & Measured at the middle of the pane & 1.16 \\
\hline 22 & Outer wall & 22.7 & Measured at wall section below the window & 0.32 \\
\hline 23 & Outer wall & 22.7 & Measured at $40 \mathrm{~cm}$ above socket level & 0.20 \\
\hline 24 & Outer wall & 22.7 & Measured $80 \mathrm{~cm}$ above bottom of wall & 0.23 \\
\hline
\end{tabular}

Equation 9 solely calculates the reduction in heat transmission losses. There are other important parameters which affect household heating energy consumption. For example, the improvement of air tightness will also have an impact on energy reduction, which cannot be captured by measuring U-values. Also, removing a few fenestration surfaces will decrease the daylight availability, which will most likely cause the frequent use of artificial lighting (increased internal gains can lead to decreased heat requirement). Replacing the glazing (which has not been done in the presented example) can also affect the available solar gains during the heating period, which also can impact overall heat requirements

The budget for upgrading the energy performance of this house was about DKK 470,000 (USD 94,000). The energy consumption (heat and electricity) totaled as much as DKK 39,000 (USD 7800) per year (including heat for a pool). Natural gas for heating in year 2009/2010 totaled 
$1906 \mathrm{~m}^{3}$ (heating of house excl. pool) corresponding to $145 \mathrm{kWh} / \mathrm{m}^{2}$ which is much more than required to a new house today in Denmark (approximately $65-70 \mathrm{kWh} / \mathrm{m}^{2}$ [23]). A small part of the house (a corridor and a bedroom) was heated by electricity with consumption in 2010 of $1354 \mathrm{kWh}$. Indoor temperature (year average) was $22{ }^{\circ} \mathrm{C}$. The saving potential on heating (gas consumption alone) was DKK 10,800 (USD 2160) per year corresponding to approximately $60 \%$ saved on the heat expenses for the main house, disregarding the swimming pool. This saving potential corresponds to the below listed measures for upgrading the energy performance [5]:

- Outer walls including sockets are insulated with $195 \mathrm{~mm}$ mineral wool which is plastered.

- One exterior door replaced by a modern entrance door with low U-value. The other exterior door is removed and the opening closed and insulated as the rest of the façade.

- House entrance was insulated with $100 \mathrm{~mm}$ insulation

- Gables and foot of roof were insulated with good connection to the ceiling insulation

- Digging up soil around the concrete foundation and in top, new foundation blocks made of lightweight concrete are established and insulated with phenolic foam (PF).

- The existing windows (with low-energy glazing) are moved out to align with the façade.

- Installation of mechanical ventilation (balanced) aggregate with heat recovery

- Air tightening of the ceiling and between ceiling and outer walls.

- Insulation of bedroom (previously insulated from inside to a certain level).

Every upgrades of energy performance must be conducted with special care to the actual building physics. The upgrades should of course not introduce new problems, such as increased moisture level in the building [24].

A number of other measurements were made on different buildings during the last seven years. Other examples on measurements are presented in [2].

\section{Limitations and Uncertainties}

Real house walls never operate at steady state conditions and therefore a single external heat flux measurement can lead to significant errors. For example, when an east-facing wall after a cold night is exposed to solar radiation, the heat flow at the outer surface can be into the building rather than out of the building. That phenomena can be checked via the U-value meter and, if present, measurements are omitted.

Stormy weather is a problem as well because of its disruptive effect on the heat transmission from the outer surface of the object to the heat absorption sensor. A measurement was made during a snowstorm with wind speed above $20 \mathrm{~m} / \mathrm{s}$. The U-value of a double-glazed window was measured to just $1.80 \mathrm{~W} / \mathrm{m}^{2} \mathrm{~K}$ instead of the expected $2.80 \mathrm{~W} / \mathrm{m}^{2} \mathrm{~K}$. Wind speeds below $10 \mathrm{~m} / \mathrm{s}$ do not influence the heat transfer environment near the facade very much, and measurements can be done with good accuracy [2].

Solar radiation direct on a façade before a measurement will result in variations. This is due to the heating of the surface, which tells nothing about the heat loss through the façade. However, the Meter will measure any heat reaching its heat absorption sensor, and therefore the sun-generated heat will disturb the results. 
Moisture in the material is another limitation in the application of the Meter. This is due to the evaporation of the moisture from surface. The evaporation requires energy, and a part of the heat loss is consumed during this evaporation process, resulting in lower measured U-values. Taking repeated measurement at different points in time may average some of the variability out of course. For this to work it may also be critical to minimize the sun exposure to the measure surface [2].

A few examples of measurements on real houses are presented in Table 2. Example $I: U_{1}, U_{2}$ and $U_{3}$ are measured over three days in February 2006 (and at different times during the day). $\mathrm{U}_{2}$ and $\mathrm{U}_{3}$ were measured in the evening around 9 p.m. $U_{1}$ was measured in daylight at about noon (1 p.m.).

The expected U-values are the classified values for the windows and a calculated value according to Danish Standard (DS/EN 12667 and DS 418 [14,25]), and made on the basis of knowledge of the structure including insulation. The measured U-values are a little above the expected values. This could be due to ageing of the materials, "collapse" of insulation and/or the windows could be measured near the edges where the heat loss is slightly larger. Uncertainties in the device do also contribute.

Example II of measurements is on a three-storied building at Technical University of Denmark (DTU). These measurements were made the 6th April 2006 during the daytime, and with only 10 minutes between the individual measurements.

Example III is a double-glazed window in a house. The measured window was about 25 years old and the window was measured several times during the start of 2005. For each of the measurements the $\mathrm{T}_{\text {in }}$ and $\mathrm{T}_{\text {out }}, \mathrm{RH}$ (Relative Humidity), weather conditions, etc., were recorded. Nine measurements were made with and average U-value of $2.87 \mathrm{~W} / \mathrm{m}^{2} \mathrm{~K}$ with standard deviation 0.06 .

Table 2. Examples of measurements.

\begin{tabular}{|c|c|c|c|c|c|c|}
\hline \multirow{2}{*}{ Examples } & Measuring Object & $\mathbf{U}_{\mathbf{1}}$ & $\mathbf{U}_{\mathbf{2}}$ & $\mathbf{U}_{\mathbf{3}}$ & Expected U & Age \\
\hline \multirow{3}{*}{ Example I } & Terrace door & 1.35 & 1.33 & 1.31 & 1.20 & 6 years \\
\cline { 2 - 7 } & Low E-glazed window & 1.24 & 1.27 & 1.30 & 1.20 & 6 years \\
\cline { 2 - 7 } & Outer wall & 1.04 & 0.97 & 0.94 & 0.90 & 32 years \\
\hline \multirow{2}{*}{ Example II } & $\begin{array}{c}\text { Double-glazed } \\
\text { window }\end{array}$ & 3.00 & 3.12 & & 2.80 & 36 years \\
\cline { 2 - 7 } & Outer wall & 0.41 & 0.42 & & 0.40 & 36 years \\
\hline & $\begin{array}{c}\text { Double-glazed } \\
\text { window }\end{array}$ & $\begin{array}{c}2.87 \text { (average of 9 } \\
\text { measurements) }\end{array}$ & & & 2.80 & 25 years \\
\hline
\end{tabular}

\section{Conclusions}

Energy efficiency, energy reduction and upgrading of the energy performance were investigated. A new heat loss measuring device, called a U-value meter, has been developed. The device was invented in 2001 and the first application to the Danish Patent Office took place in March 2002. A Danish patent was granted in 2009. The device can be utilized as a stand-alone apparatus, or in combination with thermography equipment, the latter in order to get a picture of the distribution of hot and cold locations of a building facade. However, since thermography only gives a picture of the surface temperatures, and not the heat loss distribution, the need arises for a heat loss measuring device. The device measures heat losses through the facades in the SI unit $\left[\mathrm{W} / \mathrm{m}^{2} \mathrm{~K}\right]$. By means of the measuring 
device, it is possible to achieve a more cost-effective building renovation. It is possible to check whether heat transmission coefficients (U-values) meet the requirements as stipulated in the Building Regulations. The corresponding potential reduction of the energy consumption can be calculated. A huge energy saving potential for residential houses is demonstrated during a EUDP project in a temperate region (Denmark).

The U-value meter is now planned to be utilized in the tropics for measuring the thermal performance of facades with the aim to reduce the costs to air conditioning. A project in a tropical climate in cooperation with the National University of Singapore (NUS) is initiated.

\section{References and Notes}

1. Sørensen, L.S. Varmeudveksling under brandforløb. In Brandfysik og Brandteknisk Design af Bygninger (in Danish), 1st ed.; Polyteknisk Forlag: Copenhagen, Denmark, 2004; pp. 167-198, 473-496.

2. Sørensen, L.S. Energy Renovation of Buildings Utilizing the U-value Meter, a New Heat Loss Measuring Device. Sustainability 2010, 2, 461-474.

3. Sørensen, L.S. U-value Meter (Transmission Coefficient Measuring Apparatus). European Patent Application (EPA) 1,347,289, March 2003; pp. 1-13.

4. Danish Meteorological Institute. Available online: http://www.dmi.dk (accessed on 15 March 2013).

5. EUDP-2009-II: Development of standard solutions for energy-extensive building envelope renovation of existing buildings from the period 1960-1980. A project with financial support from the Energy Technological Development and Demonstration Program (EUDP), 2009.

6. Incropera, F.P.; DeWitt, D.P.; Bergman, T.L.; Lavine, A.S. Fundamentals of Heat and Mass Transfer, 6th ed.; Wiley: Somerset, NJ, USA, 2006; Chapter 9, Table 13.3.

7. Holman, J.P. Heat Transfer, 8th ed.; McGraw-Hill Inc: New York, NY, USA, 1997; pp.123-158.

8. Gerike, A. Portable temperature sensing device. U.S. Patent 4,173,894, 13 November 1979.

9. Chuah, Y.K.; Sun, M.-T.; Huang, B.-J. Insulation measuring apparatus which forces heat flow in one direction with a constant temperature region. U.S. Patent 6,257,761, 10 July 2001.

10. Szabo, P. Method of and apparatus for the determination of the thermal insulating properties of building walls. U.S. Patent 4,647,221, 8 November 1985.

11. Poppendiek, H.F. Means and techniques useful in establishing R values in insulation. U.S. Patent 4,236,403, 2 December 1980.

12. Marechal, J.-C. Device and method for thermal measurements on walls. E.P. Patent 0,065,433, 24 November 1982.

13. DS/EN 12664. Thermal Performance of Building Materials and Products-Dry and Moist Products of Medium and Low Thermal Resistance; DS/EN-Standard, 2001.

14. DS/EN 12667. Thermal Performance of Building Materials and Products-Products of High and Medium Thermal Resistance; DS/EN-Standard, 2001.

15. Both, E.; Christiansen, G. Termodynamik (in Danish), 2nd ed.; Den Private Ingeniørfond: Lyngby, Denmark, 1995.

16. Marsh, R. Arkitektur og Energi: Mod en 2020-Lavenergistrategi (in Danish), 1st ed.; Aalborg University: Hørsholm, Denmark, 2011. 
17. Munch-Andersen, J. Efterisolering af Etageboliger (in Danish); Aalborg University: Hørsholm, Denmark, 2010.

18. DS/EN ISO 10077-2. Termisk ydeevne for vinduer, døre og skodder-Beregning af varmetransmission-Del 2: Numerisk metode for rammer (in Danish); Dansk Standard, Charlottenlund, Denmark, 2004; p. 262.

19. DS 452:1999. Termisk isolering af tekniske installationer (in Danish); Dansk Standard, Charlottenlund, Denmark, 1999.

20. DS/EN ISO 10211:2008. Kuldebroer i bygningskonstruktioner: Varmestrømme og overfladetemperaturer. Detaljerede beregninger (in Danish); Dansk Standard, Charlottenlund, Denmark, 2008.

21. Aggerholm, S.; Grau, K. Bygningers Energibehov (in Danish); Aalborg University: Hørsholm, Denmark, 2005.

22. DS 418:2002. Beregning af bygningers varmetab (in Danish); Dansk Standard, Charlottenlund, Denmark, 2002.

23. SBi. Anvisning om Bygningsreglement 2010 (in Danish); Aalborg University: Hørsholm, Denmark, 2010.

24. Dampspærrer i klimaskærmen-fugttransport og materialer (in Danish). Available online: https://byg-erfa.dk/dampspaerrer-fugttransport (accessed on 5 March 2013).

25. DS 418:2011. Beregning af bygningers varmetab (in Danish); Dansk Standard, Charlottenlund, Denmark, 2011.

26. 2002/91/EF. Direktiv om bygningers energimoessige ydeevne (in Danish). Europaparlamentets og Rådets direktiv 2002/91/EF af 16/12/2002: De Europæiske Fællesskabers Tidende, 4.1.2003. Available online: http://eur-lex.europa.eu (accessed on 4 July 2013).

(C) 2013 by the authors; licensee MDPI, Basel, Switzerland. This article is an open access article distributed under the terms and conditions of the Creative Commons Attribution license (http://creativecommons.org/licenses/by/3.0/). 